\title{
Discrete Fourier Transform (DFT)-Based Computational Intelligence Model for Urban Carbon Emission and Economic Growth
}

\author{
Chun Fu ${ }^{(D},{ }^{1}$ Xiayun Gui $\mathbb{D D}^{1},{ }^{1}$ and Farzana Akter $\mathbb{D}^{2}$ \\ ${ }^{1}$ Management School, Nanchang University, Nanchang 330000, China \\ ${ }^{2}$ Department of ICT, Bangabandhu Sheikh Mujibur Rahman Digital University, Kaliakair, Gazipur, Bangladesh \\ Correspondence should be addressed to Xiayun Gui; gxy_crcm@163.com and Farzana Akter; farzana@ict.bdu.ac.bd
}

Received 1 December 2021; Accepted 5 January 2022; Published 4 February 2022

Academic Editor: Araz Darba

Copyright (C) 2022 Chun Fu et al. This is an open access article distributed under the Creative Commons Attribution License, which permits unrestricted use, distribution, and reproduction in any medium, provided the original work is properly cited.

\begin{abstract}
Economic development leads to the widespread use of energy, which results in carbon emissions. In order to determine the correlation between different urban carbon emissions and fiscal growth, a coupling and coordination model of urban carbon emissions and economic growth based on discrete Fourier transform (DFT) is constructed. According to the coupling and coordinated development characteristics of economic growth and carbon emissions, the evaluation index system of the regional economy and carbon emissions is constructed. This paper examines the proportion of primary energy consumption and the influencing factors of carbon emission in a city and constructs the economic growth computational intelligence model and urban carbon emission model. The coupling degree among economic growth, carbon emission, and energy consumption is studied; the coupling standard between economic growth and energy consumption carbon emission is determined; and the carbon emission factor under the method of DFT is introduced. The coupling coordination model between economic growth and carbon emission is constructed, and the interaction mechanism between carbon emission, economic development, and environmental protection is determined. The experimental findings demonstrate that when energy consumption intensity and carbon emission are relatively low, the model's change in the trend of coupling coordination index is comparable with the real/actual condition and the model is more reliable.
\end{abstract}

\section{Introduction}

Carbon emission and economic development have attracted great attention from all the research communities in the world [1]. During economic growth, energy needs to be consumed constantly by the industries across the world, but the energy generation resources are limited [2]. The energy generation process also produces greenhouse gases in the process of production that may pose a threat to the survival and development of humans [3]. The governing bodies around the globe are paying enough attention to carbon emission or carbon footprints to minimize the carbon emission that directly affects the breathing air and is meticulously related to the health of people [4]. Sustainable urban development is consuming renewable energy solutions that are converting energy from one form to another for reducing carbon dioxide $\left(\mathrm{CO}_{2}\right)$ emissions [5]. However, climate changes, global warming, and the rapid rise in demand for energy have contributed to the generation of more carbon emissions. A few quantitative estimates have been fabricated from the data obtained from countries across the world regarding $\mathrm{CO}_{2}$ emissions [6]. Innovative solutions are required to address the needs of energy and to control the carbon emissions to provide a better environment for breathing and living [7]. Currently, it is unanimously recognized that urban growth can strongly impact the contribution of carbon emissions, global warming, and changes in the international weather [8]. It is naturally important to employ suitable techniques for designing innovative energy solutions by preserving the good health of the environment [9]. Therefore, the research on the coordinated development based on the computational intelligence model of the low- 
carbon economy is considered in this paper, and an innovative technique is presented to provide the solutions for the aforesaid problem. The research results are the important decision-making basis for the expansion of low-carbon economy. From the current situation of urban and rural development, with the rapid growth of the regional economy, most regions in the world are also facing the grim situation of high carbon emissions [10]. The contradiction between energy conservation and emission reduction, economic development, and environmental protection is increasing prominently [11]. It is worth establishing a correlation between economic growth and carbon emissions and correlating these factors with each other for the sustainable development of the economy. At present, the world has reached a consensus on the concept of supportable development in the sustainable environment [12]. The core of this concept is to strive for a harmonious development among society, economy, resources, and environmental protection and integrate the concept of the development of the society and economy with the resources as well as environment. In the past $20-30$ years, $\mathrm{CO}_{2}$ emission and its effects on economic growth have become one of the most discussed topics nationally as well as internationally [13]. Many research efforts are made in this area to provide solutions at different levels related to water, air, and the entire environment [14]. Therefore, to deal with the relationship between carbon emission and economic development and to deal with global climate deterioration, it is mandatory to find renewable energy generation solutions. At present, the energy consumption is beyond words, and the carbon emission is proportionately high. There is an inverse correlation between economic progress and environmental protection. The solution for reducing carbon emissions while developing the economy and safeguarding the environment has become a key subject for economic growth.

Low carbon emission and green development have become the only way of social development along with economic development [15]. To reduce carbon emissions while developing the economy and protecting the environment, the key is to deal with the coordination between carbon emissions and economic growth, and hence, we are proposing the solution in this paper. In this context, it is necessary to establish coordination between energy generation solutions and environment protection solutions. By improving the efficiency of energy generation and aiming at reducing greenhouse gas emissions, the proposed method will gradually achieve the unification of energy and the environment. However, with the increasing carbon emissions in various provinces and regions in the world, the energy conservation and emission reduction goals are on the top charter for maintaining stable and rapid economic growth that focuses on the overall development of energy utilization and reduction in carbon releases. It has significant practical importance, and various approaches, such as heuristic approaches, fuzzy-based approaches, applied mathematics, and AI-based intelligent models, have been proposed to address these problems.

The key points of the proposed research are as follows: (i) In this paper, DFT-based computationally intelligent model is proposed that is focused on showing the adverse effects of urban emission of carbon dioxide on the environment and its negative impacts on economic development

(ii) This model studies the proportion of energy consumption, carbon emission factors (CEF), and analysis of $\mathrm{CEF}$

(iii) In this paper, the proportion of primary energy consumption and its influencing factors of carbon emission in urban cities are examined

(iv) Coupling division standard between economic expansion and energy utilization carbon emission is studied and presented

(v) Correlation among economic development, carbon emission (CE), and energy generation is also examined

(vi) The changes in the rate of carbon emission intensity are also examined with the proposed method to check the effectiveness of the proposed work

The paper is organized as follows: Section 1 discusses the historical context of carbon emissions as well as the models and approaches employed by various writers to detect and reduce carbon emissions. The discrete Fourier algorithm (DFT) is discussed in Section 2. Section 3 delves into the coupling and coordination computational intelligence model of urban carbon emissions and economic growth. Section 4 contains a comprehensive experimental analysis. In the conclusion part, the outcome of the paper is illustrated.

\section{Proposed Work Based on DFT}

The discrete Fourier transform (DFT) is the discrete form that considers both the time and frequency domains [16]. In DFT, the sequences of time and frequency domains are finite, but in fact, these two sets of sequences should be considered as the main value sequences of discrete periodic variables. Even if DFT is applied to a finite discrete variable, it must be considered as a transformation of its periodic extension. In practical application, DFT is usually calculated by Fourier transform (FT) that has been originally developed for continuous variables, that is, analog variables. It is a mathematical tool used to analyze variables in the frequency domain. When real or complex numerical simulation variables are applied, it generates correlation frequency-domain functions.

The purpose of spectrum analysis is that the variables can be formed into the weighted sum of the complex exponential function (spectrum component) under the condition of handling the constraints [17]. Each frequency weighting term is the complex amplitude, and the problem can be decomposed into the sum of the sinusoidal fundamental components as the high-order sinusoidal component is an essential manifold of the fundamental frequency. The second application of DFT is to find a system's frequency response from the system's impulse response, and vice versa [18]. This 
allows the structures to be analyzed inside the frequency domain, in a similar way as the convolution allows structures to be analyzed in the time area. In this case study, the values of data using various time domains and frequency domains are determined. This assists in attaining the impulse responses and frequency responses with normalized values as well as actual values.

With the emergence of digital computers, especially microprocessors, this work can perform spectrum analysis tasks in the digital domain. However, the computer can only receive discrete sequences with limited time, so it is necessary to truncate the variables in the time domain, transmit them to the digital domain of the computer, and then solve the coupling relationship between participating variables through DFT.

A periodic sequence signal $s(x)$ and its spectrum $s\left(k \alpha_{1}\right)=G_{K}\left(\alpha_{1}=2 \pi / N, K=1,2, \ldots, N-1\right)$ are set, and $s(x)$ is expanded by Fourier series:

$$
s(x)=\sum_{K=0}^{N-1} s\left(k \alpha_{1}\right) \mathrm{e}^{N} .
$$

Its spectrum is represented by

$$
s\left(k \alpha_{1}\right)=\frac{1}{N} \sum_{K=0}^{N-1} s(x) \mathrm{e}^{N} .
$$

The spectrum density of discrete sequence signal is given in the following equation:

$$
N s\left(k \alpha_{1}\right)=\sum_{K=0}^{N-1} s(x) \mathrm{e}^{N},
$$

where $N s\left(k \alpha_{1}\right)$ is the spectral density of the periodic sequence set number $s(x)$. According to the definition of Fourier transform of a continuous signal and the idea of Fourier transform of continuous signal, the spectral density of discrete nonperiodic sequence signal is defined as discrete Fourier transform, so the definition of discrete Fourier transform is described by

$$
s(k)=\sum_{K=0}^{N-1} s(x) e^{N} .
$$

From the above transformation results, it can be seen that the length of the periodic sequence signal $s(x)$ is $N$, and its DFT $s(k)$ is still a frequency domain of finite length sequence with the length of $N$. According to the definition of DFT, it is limited between 0 and 1 .

Therefore, based on the periodic sequence signal $s(x)$, a coupling coordination computational intelligence model of carbon emission and economic growth should be constructed. The main causes of the model errors are spectrum leakage and fence effect caused by asynchronous sampling. In order to improve the measurement accuracy, it is necessary to restrain spectrum leakage or synchronize as much as possible to reduce its impact on coordination accuracy.

\section{Coupling and Coordination Model of Urban Carbon Emission and Economic Growth}

According to the characteristics of the coordinated development of economic growth and carbon emissions and the purpose of a comprehensive evaluation, the establishment of the comprehensive evaluation index model adheres to the following principles:

(1) The principle of policy relevance and comprehensiveness: Policy relevance requires that the indicator system should play a supporting and guiding role in the decision-making. It should comprehensively and objectively reflect all aspects of the coordinated development of economic growth and carbon emissions. The defined objectives should be related to the existing policy objectives, in line with the objective connotation of the coordinated development of economic growth and carbon emissions. Comprehensiveness means that the index system of coordinated development of economic growth and carbon emission should have enough coverage. Therefore, in the proposed research, we have selected the representative indicators that can reflect the theme, avoid the repeated selection amongst the indicators, and stick to the characteristics of linking the evaluation objectives and indicators.

(2) The principle of scientificity and comparability: The so-called scientificity means that the index system should be established on the basis of scientific feasibility, the data source should be accurate, and the comparability principle specifies that the processing method and the data analysis conform to the statistical standards and comparable. The specific indicators should be able to objectively and truly reflect the state of the system, and the interrelationship between subsystems and indicators can be comparable and evaluable. It should be able to evaluate the degree of coordinated development of economic growth and carbon emissions. There are no obvious scientific problems in the structure and selection of index systems [18]. The index content in our proposed work is simple and clear, strong in generality, and easy to understand and accept.

(3) Applicability and operability principle: In this, the selection of indicators should start from the regional characteristics of the selected research area, and the selection of indicators that can reflect the coordinated development of economic growth and carbon emissions should be given more attention. The concept of indicators should be clear; the calculation method should be simple; and the acquisition cost should be low.

Based on the three principles we can determine the model into three basic indexes or models as mentioned in the following. 
3.1. Regional Economy and Carbon Emission Evaluation Index. Building evaluation index model is the key to carbon emission quality evaluation. It is necessary to have a deep understanding and objective analysis of the factors and models that make up carbon emission in the evaluation area, so as to select and establish them in a targeted way [19]. Different regions have different natural conditions, forming a wide variety of natural ecosystems, and different ecosystem states have different suitability for human survival. The selection of evaluation indicators should consider the regional carbon emission quality status, characteristics, the natural background of carbon emission, and the changes in the environment due to human activities, so as to make the evaluation of carbon emission quality more comprehensive [20].

Based on the research work on carbon releases, economy and atmosphere, and relevant research outcomes, 7 pointers are designated to ascertain the complete index of carbon release, and 10 pointers are nominated to ascertain the complete index of economic expansion level from the perspective of economic scale and economic growth potential.

From the two aspects of environmental pollution and environmental governance, 10 indicators are selected to calculate the comprehensive index of environmental level. The evaluation index system is shown in Table 1:

According to the data availability and relevant results, the region is selected as the decision-making unit, and three-stage DEA is utilized to determine the carbon release efficiency. Three-index indicators of capital, energy, and labor force are nominated as the input system; GDP and carbon dioxide emissions are selected as expected output and unexpected output systems, respectively. Taking a certain year as the base period, the capital stock of each city in the region is calculated according to the constant price in ten years. The unit of capital stock is 100 million yuan; the number of employees at the end of each year is taken as the labor force element, and the unit of energy consumption is taken as the energy factor, and the unit is 10,000 tons of standard coal [18]. The expected output GDP is converted into the base period constant price by using the deflator index and adjusted to the real GDP. The selection of external environmental variables mainly considers the factors that have a significant impact on carbon dioxide emission efficiency but are not within the scope of subjective control. The proportion of fiscal expenditure in GDP is selected to represent the government's influence; the proportion of tertiary industry represents the industrial structure for carbon release; and the intensity of utilization of energy is determined with the base period as the constant price.

3.2. Construction of the Economic Growth Model. The energy consumption structure of cities dominated by coal makes the energy consumption more thoughtful. The total energy utilization has also increased substantially in the recent decade, and the carbon emission per unit GDP is also on a rapid rise, which reflects the contradiction between economic growth and carbon release [20]. The regional current situation of carbon emission, economy, and environment development is the basis of model construction. To study a city's $3 \mathrm{E}$ system comprehensively, it should be started from three directions. First of all, carbon emission is the main indicator to evaluate the carbon release status of a nation or a province. Through the calculation of carbon emission, the carbon emission intensity of a region can be inferred, so as to reflect the carbon emission status of a region. Therefore, it is necessary to explore the research of the $3 \mathrm{E}$ system from the perspective of carbon emission, economic development, and energy preservation.

In the development of the economy, the optimization of energy consumption structure has not been taken into account, resulting in an energy consumption structure that does not consider environmental constraints such as reduction in carbon emissions. Carbon dioxide mainly comes from coal combustion, while the proportion of oil and natural gas is relatively low. According to the IPCC greenhouse gas release record strategies, the emission of 1 ton of standard coal is about 2.45 tons, and the proportion of carbon dioxide produced by coal, natural gas, and oil under the same heat is about 5:4:3. Table 2 shows the proportion of primary utilization of energy in one city, namely, Nanchang.

From Table 2, it can be noticed that the energy consumption structure of the city is relatively simple. From 2008 to 2019, the proportion of raw coal consumption has been maintained between $60 \%$ and $70 \%$, while the consumption of natural gas, hydropower, and new clean energy is less than $3 \%$, resulting in excessive dependence on coal for economic development producing carbon dioxide, sulfur dioxide, and other gases. In addition, the lack of promotion and practical application of new clean energy and the simplification of energy consumption structure are also the main reasons for the high carbon emissions. From 2008 to 2019, the total energy consumption has not changed much, showing a stable upward trend. From 2008 to 2017, the total energy consumption increased steadily and reached a maximum value in 2016. Then, there was a short-term decline and reached a minimum value in 2017. During this period, due to the global economic crisis in 2018-2019, the total energy consumption has dropped again; the investment in ecological security has also increased; and consequently, the investment in ICT has been increased. The achievements in energy preservation and carbon discharge reduction are indeed remarkable. In addition, according to the data, it can be inferred that the energy consumption structure is developing in a good direction, in which the proportion of raw coal in primary energy consumption has decreased from $79.2 \%$ in 2008 to $61.2 \%$ in 2018 , and the amount of oil and natural gas in prime energy utilization has increased from $19.0 \%$ and $1.5 \%$ in 2008 to $31.0 \%$ and $3.6 \%$ in 2019 , respectively. The data show that the energy consumption structure is more reasonable, and it is developing towards high efficiency and green clean energy. According to this development 
TABLE 1: Assessment index scheme of the provincial economy and carbon release.

\begin{tabular}{lcc}
\hline Primary index & Secondary indicator & Tertiary index \\
\hline The efficiency of carbon emissions & Technical efficiency \\
Pure technical efficiency \\
Scale efficiency
\end{tabular}

Economies of scale
Per capita fixed asset investment

Per capita gross regional product Proportion of nonagricultural industry

The economic development

Per capita trade sales of customer goods

Proportion of tertiary industry

Proportion of fiscal expenditure

Economic growth potential

The GDP growth rate

The density of population Average salary of employees on the job

Energy utilization per 10,000 yuan GDP

The environmental pollution $\mathrm{SO}_{2}$ emission intensity of 10,000 yuan GDP

Industrial smoke emission Water resources per capita The average temperature Forest coverage
Comprehensive utilization rate of industrial solid waste

The environmental protection

Environmental governance Industrial dust removal capacity Green coverage in built-up areas The proportion of environmental protection investment in GDP

Table 2: Proportion of primary energy consumption in a city.

\begin{tabular}{|c|c|c|c|c|}
\hline \multirow{2}{*}{ Years } & \multirow{2}{*}{ Total energy consumption (tons of standard coal) } & \multicolumn{3}{|c|}{ Proportion of primary energy consumption (\%) } \\
\hline & & The raw coal & Oil & Natural gas \\
\hline 2008 & $12,454.0$ & 79.2 & 19.0 & 1.5 \\
\hline 2009 & $12,883.3$ & 71.3 & 24.1 & 1.5 \\
\hline 2010 & $14,228.0$ & 71.4 & 24.3 & 1.2 \\
\hline 2011 & $15,757.9$ & 73.2 & 22.6 & 1.2 \\
\hline 2012 & $16,925.7$ & 73.1 & 22.7 & 1.3 \\
\hline 2013 & $18,172.5$ & 73.0 & 22.5 & 1.2 \\
\hline 2014 & $19,856.4$ & 67.9 & 27.3 & 1.3 \\
\hline 2015 & $21,492.1$ & 65.3 & 29.0 & 2.4 \\
\hline 2016 & $22,313.9$ & 61.3 & 31.6 & 3.8 \\
\hline 2017 & $20,499.6$ & 62.5 & 28.2 & 5.0 \\
\hline 2018 & $20,585.7$ & 62.1 & 28.2 & 5.4 \\
\hline 2019 & $20,522.1$ & 61.2 & 31.0 & 3.6 \\
\hline
\end{tabular}

trend, the future energy consumption structure will be more reasonable; the carbon emissions will be controlled; and the environmental level will be improved.

Based on the above, the economic growth model is determined by taking the carbon emission factor as the periodic sequence signal $s(x)$, as shown in the following equation:

$$
Q=\max s(x)_{1}\left[\beta E^{-1}+(1-\beta) I\right] s(x)_{2},
$$

where $s(x)_{1}, s(x)_{2}$, respectively, represent the row and column vectors of the collected signals of the economic growth cycle; $\beta$ represents the input coefficient of annual economic final products; and $E^{-1}$ represents the matrix of direct consumption coefficient.
The carbon emission and the economic growth can be calculated for a certain region using the above two models, but this paper focuses on the effects of emission on growth specifically in the urban areas.

3.3. Construction of the Urban Carbon Emission Model. Combined with the specific situation, the difference in carbon emission efficiency after eliminating environmental factors is more obvious [17]. Hence, the cities are divided into two categories according to carbon emission efficiency. Starting from economic factors, scientific and technological factors, institutional factors, industrial structure, economic 
scale, to scientific and technological investment as the influencing factors of energy conservation and emission reduction, the influencing factors of carbon emission are analyzed. The results are displayed in Table 3.

The analysis of carbon emission is carried out using Table 3 that implies various factors affecting carbon emission in specifically category 2 areas. The factors that are used to calculate carbon emission are industrial structure, scale of economy, science and technology, and the degree of openness of that area to the outside world. On the basis of these factors, coefficients and standard errors are also calculated. According to the research results in the table, the following can be inferred:

(1) Industrial organization has an undesirable impact on the two types of regions, and the influence on the carbon release efficiency of the first type of regions exceeds the significance level of $1 \%$, which indicates that the industrial structure dominated by the second industry is not encouraging to the development of carbon release efficiency of each region. For every 1 percentage point increase in the industrial structure, the carbon emission efficiency of the first category of regions is reduced by 0.019 percentage points, and that of the second category is reduced by 0.007 percentage points, which indicates that proper adjustment of the proportion of the second industry is conducive to improving the carbon emission efficiency of each region. However, rendering to the applicable data, the quantity of the ancillary industry began to decline significantly in 2014, an overall decline of $73.3 \%$ compared with the previous year. On the surface, the adjustment of industrial structure has been effective, but the economic development has always relied on the secondary industry. Thus, it can be seen that the adjustment of industrial structure should be performed stepwise, not overnight.

(2) The impact of economic scale on the first category of areas is positive, and the impact on the second category of areas is negative, and the impact on the efficiency of carbon release of the second category of areas exceeds the significance level of $1 \%$. For each percentage point increase in economic scale, the carbon emission efficiency of the first category of developed areas is increased by 0.007 percentage points, while that of the second category is decreased by 0.582 percentage points. The reason is that the first kind of regions with strong economic strength begin to pay attention to resource development and environmental problems after the economy reaches a certain level and gradually change the extensive economic development mode; while the second kind of underdeveloped regions focus on the pursuit of economic development, still they take the extensive economic development mode and ignore the resource and environmental problems. This is an inevitable stage in the process of development. Therefore, these regions should speed up economic development, and only after the economic development reaches a certain level can they change this mode.

(3) The impact of science and technology investment on the first and second categories of regions is positive, and the impact on carbon emission efficiency of the two categories of regions is more than $1 \%$ significant level, which shows that science and technology is an effective way to improve carbon emission efficiency. The scientific and rational input of final products has a greater impact on the first category of regions, which shows that the space for improving carbon emission efficiency in these regions is limited after the economic development reaches a certain level. Increasing product input, that is to say, accelerating economic growth is the most direct and effective way to improve carbon emission efficiency in the first category of regions.

(4) There is a negative impact on the two types of provinces, that is, the higher the degree of opening to the outside world, the lower the carbon release efficiency of each province.

Based on the above content, the urban carbon emission model is determined based on the carbon emission factor as the periodic sequence signal $s(x)$, as follows:

$$
C=\max s(x)_{C 1}\left[\beta E^{-1}+(1-\beta) I\right] s(x)_{C 2},
$$

where $s(x)_{C 1}, s(x)_{C 2}$, respectively, represent the row and column vectors of the signal unit of the urban carbon emission cycle sequence.

The range standardization method is used to eliminate the order of magnitude and dimension of indicators, and AHP and differential coefficient of variation methods are comprehensively selected to prioritize the importance of the factors. The subjective and objective weights are taken as 0.5 to calculate the weight of each indicator, so as to complete the construction of economic growth and urban carbon emission model index model.

\subsection{Construction of the Coupling Coordination Model. Let $\sigma$} denote the coupling degree among economic expansion, carbon release, and energy utilization, and the value is between 0 and 1 . When $C=1$, it means that the three systems are in the best coupling state; when $C=0$, it means that all elements in the system are independent, and the system develops disorderly. As an important indicator to reflect the coordinated development of the system coupling, coupling degree can be used to distinguish the coordinated degree of provincial energy utilization carbon releases and economic expansion coupling and the stage of coupling. At the same time, the coupling stage of economic growth and energy consumption carbon emission system is divided into five stages. See Table 4 for the specific division criteria.

Because the coupling degree only describes the interaction degree among economic growth, carbon release, and energy utilization and cannot reflect the level of coupling coordination, the carbon emission factor $s(x)$ under the 
TABLE 3: Analysis of carbon emission factors.

\begin{tabular}{|c|c|c|c|c|c|c|}
\hline \multirow{2}{*}{ Factors affecting } & \multicolumn{3}{|c|}{ Category 1 area } & \multicolumn{3}{|c|}{ Category 2 area } \\
\hline & Coefficient & Standard error & Significant & Coefficient & Standard error & Significant \\
\hline Constant term & 1.2237 & 0.8687 & $* * *$ & 0.8305 & 0.1663 & $* * *$ \\
\hline The industrial structure & -0.0192 & 0.0157 & ns & -0.0068 & 0.0033 & ns \\
\hline Economies of scale & 0.0071 & 0.0054 & $* * *$ & -0.0582 & 0.0297 & $* * *$ \\
\hline Science and technology & 1.6870 & 0.2449 & $* *$ & 0.0700 & 0.3027 & $* * *$ \\
\hline Degree of openness to the outside world & -0.0069 & 0.0010 & ns & -0.0053 & 0.0027 & ns \\
\hline
\end{tabular}

*** Extremely significant. ${ }^{* *}$ Very significant. ${ }^{*}$ Significant. ns: not significant.

DFT method is introduced. Because the constraint conditions of the economic growth model (5) and the city carbon emission model (6) are the same, if we pursue the maximum economic growth and the minimum carbon emission at the same time, therefore, the DFT method is used to build the coupling and coordination model of economic growth and carbon emissions represented in the following equation:

$$
\lambda=\frac{Q}{C}=\frac{\max s(x)_{1}\left[\beta E^{-1}+(1-\beta) I\right] s(x)_{2}}{\max s(x)_{C 1}\left[\beta E^{-1}+(1-\beta) I\right] s(x)_{C 2}} .
$$

According to equation (7), the interaction and mutual restriction among carbon emission, economic growth, and ecological fortification can be determined, as shown in Figure 1.

First of all, economic development provides financial and technical support for carbon emissions, which is conducive to refining carbon releasing efficiency, improving carbon productivity, and encouraging energy preservation and emission reduction. On the other hand, carbon emissions react to the economy, which shows that if the GDP output per unit carbon emission is more (i.e., carbon emission efficiency), there would be lesser constraints on economic expansion, and these factors will be more conducive to the economic development. On the contrary, it means that economic development will consume more energy plus carbon emissions and restricts economic development. Economic development can reduce energy consumption, pollution, and pressure on the ecological environment by providing financial and technical support. However, economic development can also cause air, water, plants, and other pollution. The greater the degree of human intervention, the deeper the harm to nature will be. On the other hand, the ecological environment provides natural resources and material guarantees for economic development, which is the foundation of economic expansion. But, once the environment is polluted, the higher cost of environmental governance increases the economic burden. The higher the carbon emission is, the more fossil energy will be consumed. The carbon dioxide will produce a greenhouse effect, leading to a series of ecological environmental problems such as global warming, glacier melting, and water resource shortage. Therefore, controlling carbon emission becomes a necessary measure for environmental protection. On the other hand, the green plants in the natural environment convert the carbon dioxide absorbed into oxygen through photosynthesis, reducing the amount of carbon dioxide, and the natural seawater, soil, and other spheres can also absorb carbon emissions [19]. Therefore, the environment is the base of fiscal growth and carbon emission reduction; economic development is important support; and carbon emission is the key. Renewable energy solutions are necessary to protect the environment along with economic growth. It is of countless implications for promoting the sustainable development of the regional social economy to learn the coupling and harmonization relationship of carbon release, economic growth, and ecological protection.

\section{Results and Discussion}

In order to verify the effectiveness of the research on the coupling and coordination model of urban carbon emission and economic growth based on DFT, an experimental verification analysis is carried out.

4.1. Experiment Preparation. According to the prediction model, three cases of economic development $Q$, carbon emission $C$, and energy structure $R$ gradient are designed, and the three parameters are combined in different cases, and a total of 27 combination results are obtained shown in the following equation:

$$
S=(Q, C, R) .
$$

The specific combination is shown in Table 5 .

In this study, through comparative analysis of each situation, we understand the possible carbon emission path in the future and seek a low-carbon economic development model that does not affect economic development and has low carbon emission.

4.2. Analysis of Experimental Results. Based on two cities (city "A" and city "B") in 2013 and 2018, the coupling and coordination effect of urban carbon emission and economic growth based on DFT is studied. The changing rate of carbon release intensity obtained by the two cities is shown in Table 6:

It can be seen from Table 6 that under different conditions, the two cities have given different rates of change of carbon emission intensity. According to the actual situation of the two cities, the change trend of the coupling coordination index of urban carbon emission and economic growth is obtained, as shown in Figures 2 and 3.

When the amount of economic change is positive, the coupling coordination index is smaller, and then the relationship between economic development and the environment is more harmonious. The larger the coupling coordination index is, the worse the relationship between them. According to the changing trend of coordination index, from 2014 to 2019, the coupling coordination index 
TABLE 4: Coupling division standard between economic expansion and energy utilization carbon emission.

\begin{tabular}{|c|c|c|}
\hline $\begin{array}{l}\text { The value of } \\
\text { C }\end{array}$ & Coupling phase & Detailed description \\
\hline$\sigma=0$ & Uncoupled stage & There is no correlation between the systems. \\
\hline $0<\sigma \leq 0.3$ & Low-level coupling & $\begin{array}{l}\text { Lower economic growth and lower carbon emissions go hand in hand and are in the stage of } \\
\text { no decoupling at a lower level. }\end{array}$ \\
\hline $0.3<\sigma \leq 0.5$ & Rivalry phase & $\begin{array}{l}\text { With the rapid development of the economy, carbon emissions are also growing at a } \\
\text { relatively faster rate, and economic development and carbon emissions are in a stage of } \\
\text { relatively decoupling from each other. }\end{array}$ \\
\hline $0.5<\sigma \leq 0.8$ & $\begin{array}{l}\text { Running-in and benign } \\
\text { coupling stage }\end{array}$ & $\begin{array}{l}\text { The rapid growth of carbon emissions leads to the strengthening of citizens' awareness of } \\
\text { ecological safeguard and the slowdown of economic growth. The overall trend of higher } \\
\text { economic growth and lower carbon emissions is parallel, and the two tend to be well } \\
\text { coupled. At the same time, they are in the stage of developing from relative decoupling to } \\
\text { absolute decoupling. }\end{array}$ \\
\hline $0.8<\sigma \leq 1$ & High-level coupling & Economic development is absolutely decoupled from carbon emissions. \\
\hline
\end{tabular}

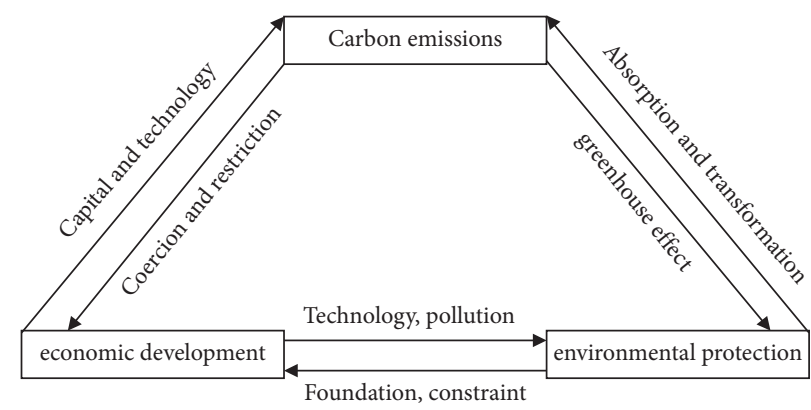

FIGURE 1: Interaction mechanism of carbon emission, economic development, and environmental protection.

TABLE 5: Combination results of three parameters in different situations.

\begin{tabular}{|c|c|c|c|}
\hline Economic development & Carbon emission (CE) & Energy structure & Corresponding situation \\
\hline \multirow{9}{*}{ Low output } & \multirow{3}{*}{ Low CE efficiency } & Low emission (LE) & Situation $1(\mathrm{~S} 1)$ \\
\hline & & Middle emissions (ME) & Situation 2 (S2) \\
\hline & & High emissions (HE) & Situation 2 (S2) \\
\hline & \multirow{3}{*}{ Middle CE efficiency } & LE & Situation 4 (S4) \\
\hline & & $\mathrm{ME}$ & Situation 5 (S5) \\
\hline & & $\mathrm{HE}$ & S6 \\
\hline & \multirow{3}{*}{ High carbon emission efficiency } & LE & S7 \\
\hline & & $\mathrm{ME}$ & S8 \\
\hline & & $\mathrm{HE}$ & S9 \\
\hline \multirow{9}{*}{ Middle output } & \multirow{3}{*}{ Low CE efficiency } & LE & S10 \\
\hline & & $\mathrm{ME}$ & S11 \\
\hline & & $\mathrm{HE}$ & S12 \\
\hline & \multirow{4}{*}{ Middle carbon emission efficiency } & LE & S13 \\
\hline & & $\mathrm{ME}$ & S14 \\
\hline & & $\mathrm{HE}$ & S15 \\
\hline & & LE & S16 \\
\hline & \multirow[t]{2}{*}{ High carbon emission efficiency } & $\mathrm{ME}$ & S17 \\
\hline & & $\mathrm{HE}$ & S18 \\
\hline \multirow{9}{*}{ High output } & \multirow{3}{*}{ Low CE efficiency } & LE & S19 \\
\hline & & $\mathrm{ME}$ & S20 \\
\hline & & $\mathrm{HE}$ & S 21 \\
\hline & \multirow{4}{*}{ Middle carbon emission efficiency } & LE & S22 \\
\hline & & $\mathrm{ME}$ & S23 \\
\hline & & $\mathrm{HE}$ & $\mathrm{S} 24$ \\
\hline & & $\mathrm{LE}$ & $\mathrm{S} 25$ \\
\hline & \multirow[t]{2}{*}{ High carbon emission efficiency } & $\mathrm{ME}$ & S26 \\
\hline & & $\mathrm{HE}$ & S27 \\
\hline
\end{tabular}


TABLE 6: Change rate of carbon emission intensity.

\begin{tabular}{|c|c|c|c|c|c|}
\hline \multirow{2}{*}{\multicolumn{2}{|c|}{ Energy consumption emission }} & \multicolumn{2}{|c|}{2013} & \multicolumn{2}{|c|}{2018} \\
\hline & & City A & City B & City A & City B \\
\hline \multirow{3}{*}{ Low energy consumption } & Low emission & -21.08 & -18.34 & -21.96 & -20.11 \\
\hline & Middle emissions & -20.35 & -17.62 & -21.43 & -19.86 \\
\hline & High emissions & -19.62 & -16.90 & -20.91 & -19.11 \\
\hline \multirow{3}{*}{ Middle energy consumption } & LE & -20.12 & -19.44 & -20.50 & -19.42 \\
\hline & ME & -19.38 & -18.34 & -19.96 & -18.62 \\
\hline & HE & -18.64 & -17.66 & -19.43 & -18.22 \\
\hline \multirow{3}{*}{ High energy consumption } & LE & -19.16 & -18.32 & -19.04 & -17.94 \\
\hline & ME & -18.41 & -17.69 & -18.49 & -17.23 \\
\hline & $\mathrm{HE}$ & -17.66 & -16.70 & -17.95 & -16.89 \\
\hline
\end{tabular}

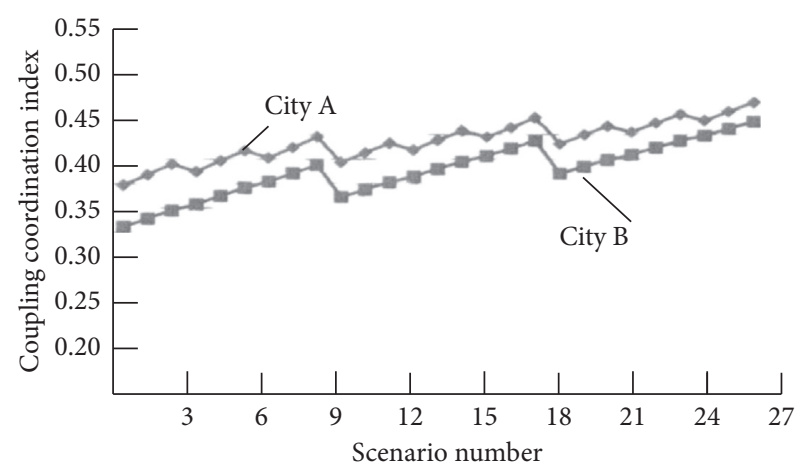

FIgURE 2: Change trend of coupling coordination index of two cities in 2013.

measured by city A is between 0.322 and 0.475 . The lowest coupling coordination index belongs to case 1 in 2019, that is, low output, low energy consumption, and low emission. During 2014-2019, the coupling coordination index measured by city B is between 0.275 and 0.443 . The lowest coupling coordination index belongs to case 1 in 2019. However, the experimental region is in the phase of quick expansion. Although the coupling and coordination index is low, it belongs to the situation of low output, and the economic output is relatively low, which is not the optimal development mode of the region. However, case 10, that is, low energy consumption and low emission of medium output, has a coupling coordination index of 0.373 , which is not the lowest, but compared with other development models, this development model belongs to medium speed development with relatively fast development speed and relatively low energy consumption intensity with minimal carbon emission. This can be considered as the development path that can be selected for this region. Therefore, the coupling coordination index measured by city $B$ is more suitable for this region.

The energy generation solutions and their impact on carbon emissions are directly proportional. Figure 4 presents the aggregate energy consumption of two cities and respective carbon emissions released from the energy solutions. It can be seen that the relationship is positively proportionate. As the consumption of energy increases, consequently, the carbon emissions are also increasing.

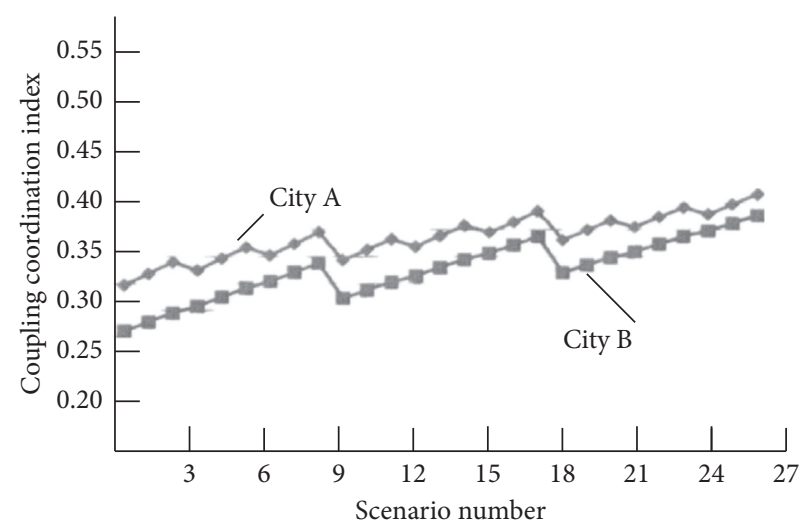

FIGURE 3: Change trend of coupling coordination index of two cities in 2018.

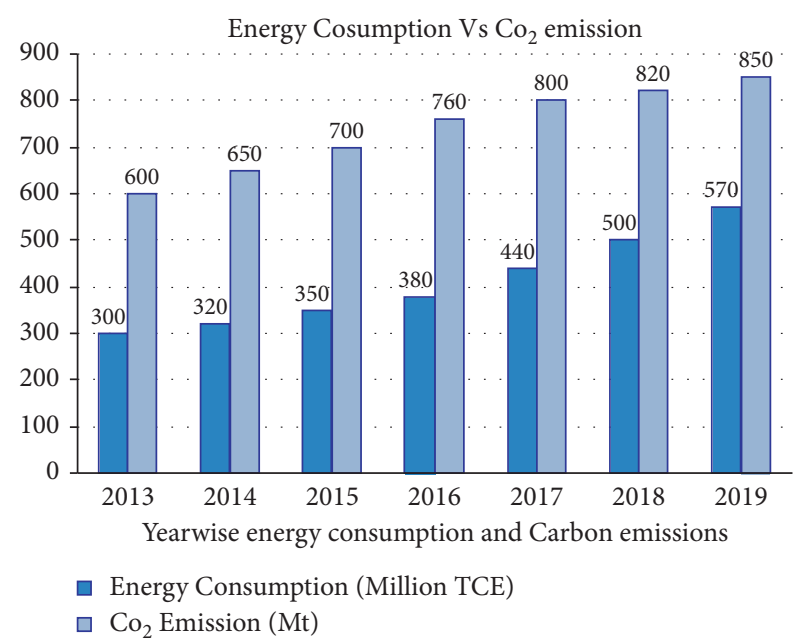

FIGURE 4: Year-wise energy consumption and carbon emissions for two cities in aggregated form.

\section{Conclusions}

Through index selection, this paper analyzes the influencing factors of urban carbon emission due to economic growth and industrialization. The coupling and coordination relationship between economic development and carbon emission is also established that provides theoretical guidance for the urban city to follow the low-carbon economic 
development path. However, due to many uncertainties, changing policies, and a limited level of knowledge, there are still some constraints that have not been taken up in this research study, which may need further in-depth analysis. The work of this paper mainly focuses on the following aspects: (1) the influencing factors of carbon emissions are based on the selected parameters such as economic effect, population effect, energy effect, and technology effect, while the research on the influence of micro factors is not considered. (2) In order to improve the research of carbon emission reduction strategy, we have attempted to show the impact of influencing factors on energy generation and on reduction of carbon emission. (3) Carbon release reduction aim is essentially focusing on $\mathrm{CO}_{2}$ release per unit of GDP, that is, carbon release intensity. However, there are very few domestic studies on the influencing factors of carbon emission intensity, but none of the study is considering all the possible factors that may influence energy generation solutions as well as $\mathrm{CO}_{2}$ releases. Our proposed work provides index-based indicators that can help the urban area decide upon energy generation solutions by keeping the carbon emissions minimal.

\section{Data Availability}

Data are restricted to share, but the fields and output are available upon request to the corresponding author.

\section{Conflicts of Interest}

The authors declare that there are no conflicts of interest.

\section{Acknowledgments}

This research was partially supported by "Research on the Competitiveness of Green Development in Central China from the Perspective of Coordination."

\section{References}

[1] T. S. Adebayo, A. A. Awosusi, D. Kirikkaleli, G. D. Akinsola, and M. N. Mwamba, "Can $\mathrm{CO}_{2}$ emissions and energy consumption determine the economic performance of South Korea? A time series analysis," Environmental Science and Pollution Research, vol. 28, no. 29, Article ID 38969, 2021.

[2] M. Alharthi, E. Dogan, and D. Taskin, "Analysis of $\mathrm{CO}_{2}$ emissions and energy consumption by sources in MENA countries: evidence from quantile regressions," Environmental Science and Pollution Research, vol. 28, no. 29, Article ID 38901, 2021.

[3] Y. Li, X. Yang, Q. Ran, H. Wu, M. Irfan, and M. Ahmad, "Energy structure, digital economy, and carbon emissions: evidence from China," Environmental Science and Pollution Research, vol. 28, no. 45, Article ID 64606, 2021.

[4] R. Khoie, A. Bose, and J. Saltsman, "A study of carbon emissions and energy consumption of wind power generation in the Panhandle of Texas," Clean Technologies and Environmental Policy, vol. 23, no. 2, pp. 653-667, 2021.

[5] T. Güney and E. Üstündağ, "Wind energy and $\mathrm{CO}_{2}$ emissions: AMG estimations for selected countries," Environmental Science \& Pollution Research, 2021.
[6] X. Zhang, H. Zhang, and J. Yuan, "Economic growth, energy consumption, and carbon emission nexus: fresh evidence from developing countries," Environmental Science and Pollution Research, vol. 26, no. 25, Article ID 26367, 2019.

[7] M. Musah, Y. Kong, I. A. Mensah, S. K. Antwi, and M. Donkor, "The link between carbon emissions, renewable energy consumption, and economic growth: a heterogeneous panel evidence from West Africa," Environmental Science and Pollution Research, vol. 27, no. 23, Article ID 28867, 2020.

[8] M. K. Khan, M. I. Khan, and M. Rehan, "The relationship between energy consumption, economic growth and carbon dioxide emissions in Pakistan," Financial Innovation, vol. 6, no. 1, p. 1, 2020.

[9] A. Lajunen, "Evaluation of energy consumption and carbon dioxide emissions for electric vehicles in Nordic climate conditions," in Proceedings of the 2018 Thirteenth International Conference on Ecological Vehicles and Renewable Energies (EVER), pp. 1-7, Monte Carlo, Monaco, April 2018.

[10] R. Rana and M. Sharma, "On the causality between electricity generation, energy consumption, investment patterns and $\mathrm{CO}_{2}$ emissions in India," in Proceedings of the 2018 2nd European Conference on Electrical Engineering and Computer Science (EECS), pp. 71-75, Bern, Switzerland, December 2018.

[11] C. Cappiello, S. Datre, M. Fugini et al., "Monitoring and assessing energy consumption and $\mathrm{CO}_{2}$ emissions in cloudbased systems," in Proceedings of the 2013 IEEE International Conference on Systems, Man, and Cybernetics, pp. 127-132, Manchester, UK, October 2013.

[12] V. Kolev, I. Draganova-Zlateva, and D. Gospodinova, "Trends in energy efficiency and $\mathrm{CO}_{2}$ emissions according to Bulgarian national energy efficiency plan," in Proceedings of the 2019 11th Electrical Engineering Faculty Conference (BulEF), pp. 1-6, Varna, Bulgaria, September 2019.

[13] M. Katona and R. Radnai, "Primary energy consumption and $\mathrm{CO}_{2}$ emission of internal combustion engine and electric vehicles," in Proceedings of the 2017 6th International Youth Conference on Energy (IYCE), pp. 1-5, Budapest, Hungary, June 2017.

[14] M. Salari, R. J. Javid, and H. Noghanibehambari, “The nexus between $\mathrm{CO}_{2}$ emissions, energy consumption, and economic growth in the U.S," Economic Analysis and Policy, vol. 69, pp. 182-194, 2021.

[15] L. Jiang, S. R. Sakhare, and M. Kaur, "Impact of industrial 4.0 on environment along with correlation between economic growth and carbon emissions," International Journal of System Assurance Engineering, 2021.

[16] M. Kaur and S. Kadam, "Discovery of resources over Cloud using MADM approaches," International Journal for Engineering Modelling, vol. 32, no. 2-4, pp. 83-92, 2019.

[17] D. Kirikkaleli, H. Güngör, and T. S. Adebayo, "Consumptionbased Carbon Emissions, Renewable Energy Consumption, Financial Development and Economic Growth in Chile," Business Strategy and Environment, 2021.

[18] F. J. Hasanov, Z. Khan, M. Hussain, and M. Tufail, "Theoretical Framework for the Carbon Emissions Effects of Technological Progress and Renewable Energy Consumption," Sustainable Development, vol. 29, 2021.

[19] O. E Olubusoye, D Musa, and S Ercolano, "Carbon emissions and economic growth IN africa: are they related?" Cogent Economics \& Finance, vol. 8, 2020.

[20] M. W. M. Roos, "Endogenous economic growth, climate change and societal values: a conceptual model," Computational Economics, vol. 52, no. 3, pp. 995-1028, 2018. 